\title{
Effects of cyclic heat treatment and aging on superelasticity in oligocrystalline Fe-Mn-Al-Ni shape memory alloy wires
}

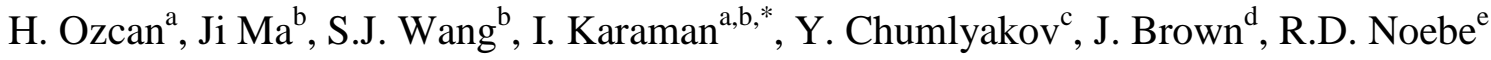 \\ ${ }^{a}$ Department of Mechanical Engineering, Texas A\&M University, College Station, TX, USA \\ ${ }^{\mathrm{b}}$ Department of Materials Science and Engineering, Texas A\&M University, College Station, TX, USA \\ ${ }^{\mathrm{c}}$ Siberian Physical Technical Institute, Tomsk 634050, Russia \\ ${ }^{\mathrm{d}}$ Dynalloy, Inc., Costa Mesa, CA., USA \\ ${ }^{\mathrm{e}}$ NASA Glenn Research Center, Cleveland, OH., USA \\ *Corresponding author: ikaraman@tamu.edu
}

\begin{abstract}
The effects of nano-precipitation on stress-induced martensitic transformation (SIM) in $\mathrm{Fe}_{43.5} \mathrm{Mn}_{34} \mathrm{Al}_{15} \mathrm{Ni}_{7.5}$ shape memory alloy wires were investigated. It was shown that a large grain size to wire diameter ratio, i.e. an oligocrystalline structure, is necessary to obtain superelasticity. The critical stress for SIM and tensile strength at room temperature increase with aging time at $200^{\circ} \mathrm{C}$ without loss of superelasticity. A superelastic strain of $6.7 \%$, with tunable transformation stress level as high as $600 \mathrm{MPa}$, and a low stress hysteresis, was obtained in the aged wires.

Keywords: Superelasticity; Martensitic transformation; Iron-based shape memory alloys; Stress induced martensite; Grain growth

Shape memory alloys (SMAs) are unique class of materials that display large reversible shape changes upon mechanical loading/unloading, i.e. superelasticity, enabled by a stressinduced martensitic transformation. NiTi alloys are the most well-known SMAs, which can exhibit up to $10 \%$ superelastic strain. They demonstrate reasonable ductility and relatively low elastic anisotropy [1,2]. However, they are difficult to cold work due to their ordered intermetallic structure [3]. In addition, they are highly composition-sensitive on the nickel-rich side of the stoichiometry, where 0.1 at. $\%$ change in composition leads to a $20^{\circ} \mathrm{C}$ change in transformation temperatures [4]. Besides the high cost of initial materials, difficulty of processing and the need to precisely control the chemistry further increases the cost and hinders the widespread use of NiTi.
\end{abstract}


Disordered Fe-based SMAs are alternatives to NiTi due to their inexpensive constituents and ease of processing. Since 1970s, many attempts have been made to develop Fe-based SMAs. However, only a few were successful in achieving superelasticity at room temperature. Maki et al. [5] were able to show reversible martensitic transformation by ausaging an FeNiCoTi alloy to form fine precipitates, however, they observed superelasticity only at $-100^{\circ} \mathrm{C}$. A major breakthrough came in 2010, in the form of a polycrystalline FeNiCoAlTaB alloy [6]. This material exhibits room temperature superelasticity of up to $13.5 \%$ strain, but requires a strong [100] texture, coherent nano-precipitates, and large grain size to achieve superelasticity. In 2011, a new FeMnAlNi alloy was developed [7] that exhibits 5\% room temperature superelasticity, but its performance is also dependent on nano-precipitates and large grain size. In single crystalline FeMnAlNi alloys, the effects of aging on the superelastic properties were studied by Tseng et al. [8]. They found that superelasticity, recoverable strain level, and stress hysteresis are controlled by the size of the precipitates. A unique feature of this alloy is a small temperature dependence of the critical stress for stress-induced martensitic transformation $\left(\sigma_{\mathrm{SIM}}\right)$ of $0.41 \mathrm{MPa} /{ }^{\circ} \mathrm{C}$, which is almost 15 times smaller than that of NiTi [9]. This characteristic is crucial for structural and civil infrastructure applications that require a stable superelastic response over a broad temperature range.

Fe-based SMAs, on the other hand, usually suffer from large elastic and transformation strain anisotropy similar to $\mathrm{Cu}$-based SMAs [10-13]. This leads to high internal stresses at grain boundaries between grains with large orientation mismatches upon martensitic transformation $[11,14]$. Additionally, most of the Fe-based SMAs have a limited number of martensite variants [15]. Therefore, strain accommodation at grain boundaries during the transformation becomes more difficult and, together with high stresses, causes intergranular fracture and/or a suppression of superelastic behavior $[11,14,16]$.

Thus, to obtain good superelasticity, it is, thus, necessary to decrease the total grain boundary area and triple junctions, and limit the effect of grain boundary constraint during the transformation [7,17-19]. Ueland et al. [17,18,20] and Chen et al. [21] produced bamboo structured microwires and obtained $7 \%$ superelasticity in $\mathrm{Cu}-\mathrm{Al}-\mathrm{Ni}$ microwires. Similarly, in Febased SMAs, it has been shown that grain size to wire diameter (d/D) [19] or grain size to sheet thickness ratios larger than one [7] is a necessary condition to obtain superelasticity. 
Techniques to obtain large grain size through abnormal grain growth in FeMnAlNi SMAs involve cyclic heat treatments where samples are repeatedly cycled between the single phase and two phase regions in the phase diagram. Omori et al. [19] annealed FeMnAlNi wires and sheets at $1200^{\circ} \mathrm{C}$ followed by air cooling, and repeated this process until they obtained large grain size. Vollmer et al. [16] have applied similar cyclic heat treatments, cycled between $1200^{\circ} \mathrm{C}$ and $900^{\circ} \mathrm{C}$ and obtained coarse grains in the FeMnAlNi flat, thin tension specimens.

Few studies on FeMnAlNi polycrystals have recently focused on suppressing intergranular fracture [16,19] and investigating the effect of grain size on superelastic behavior. Additionally, it has been shown that various aging treatments on FeMnAlNi single crystals improves the mechanical response and superelastic behavior [9]. However, the latter has not been studied in polycrystalline / oligocrystalline FeMnAINi SMAs. In the present work, we investigate the effect of post-cyclic heat treatment and nano-precipitation on the superelastic behavior and mechanical properties of FeMnAlNi polycrystalline wires.

Ingots with a nominal composition of $\mathrm{Fe}-34 \% \mathrm{Mn}-15 \% \mathrm{Al}-7.5 \% \mathrm{Ni}$ (at.\%) were prepared by vacuum induction melting. To enable wire drawing of the FeMnAlNi at room temperature it is necessary to create a two-phase microstructure consisting of a bcc alloy matrix containing ductile fcc second phase. To generate this microstructure, the ingots were first hot extruded at $1000{ }^{\circ} \mathrm{C}$ with an area reduction ratio of $7: 1$. The resulting rods were then solution treated at $1200^{\circ} \mathrm{C}$ and annealed at $900^{\circ} \mathrm{C}$ for $30 \mathrm{~min}$ under high purity argon followed by a water quench (Fig.1a). The $900^{\circ} \mathrm{C}$ treatment was performed to introduce the high volume fraction of ductile second phase particles necessary for wire drawing. The heat treated rod was then cold-drawn into wire with a final diameter of $0.5 \mathrm{~mm}$, following an area reduction of $75 \%$. Final chemical composition of the wires was determined using Wavelength Dispersive Spectroscopy (WDS) and compositional variations were found to be less than 0.2 at.\% from the nominal.

To promote abnormal grain growth, the wires were encapsulated in quartz tubes, evacuated, and filled with high-purity argon and then subjected to cyclic heat treatments. The encapsulated wires were cycled five times between the single phase region $\left(1200^{\circ} \mathrm{C}\right)$ and room temperature, by placing the encapsulated wires in a pre-heated furnace for $0.5 \mathrm{hrs}$ and removing them from furnace and cooling down to room temperature in air. After these steps, the encapsulated wires were solution heat treated (SHT) at $1300^{\circ} \mathrm{C}$ for $30 \mathrm{~min}$ and quenched in 
water. Finally, nano-sized precipitates were formed with precipitation heat treatments at $200^{\circ} \mathrm{C}$ for 1, 3, 5 and 24 hours.

Microstructure of the wires was investigated using a Keyence digital microscope. Specimens for optical microscopy were prepared by mechanical grinding and polishing through $0.25 \mu \mathrm{m}$ diamond paste followed by a final polish using $0.04 \mu \mathrm{m}$ colloidal silica. Finally, samples were etched using a solution of $4 \%$ nitric acid and $96 \%$ ethanol by volume. Transmission electron microscopy (TEM) samples were prepared by twin-jet electro-polishing with a solution of $30 \%$ nitric acid and $70 \%$ methanol by volume at $-20^{\circ} \mathrm{C}$. TEM investigations were conducted using a FEI Tecnai $\mathrm{G}^{2}$ F20 electron microscope. Crystallographic texture was measured using electron Backscatter Diffraction (EBSD) technique conducted at room temperature on a Tescan FERA-3 scanning electron microscope (SEM) with an accelerating voltage of $20 \mathrm{kV}$. EBSD samples were prepared identically to those for optical microscopy.

To promote a superelasticity in these alloys, the grain size to wire diameter ratio must be larger than 1 [19]. The final grain sizes and distribution in a representative wire are shown in Fig.1b where the oligocrystalline wire with bamboo structured grains can be seen. The grains have a large average $\mathrm{d} / \mathrm{D}$ ratio of $\sim 8$. The microstructure contains a small number of triple junctions and the number density of grain boundaries is small. The majority of the grain boundaries are perpendicular to the wire axis and span the cross section of the wire. Fig.1c shows that FeMnAlNi wire possesses strong [110] texture in the drawing direction after cyclic abnormal grain growth followed by solution heat treatment.

In addition to large grains, nano-sized B2 precipitates (as evidenced in the selected area diffraction pattern in Fig.2c) are also prerequisite for superelasticity in the FeMnAlNi alloys. The volume fraction and size of these precipitates greatly influence the superelastic characteristics, such as transformation stress levels, transformation temperatures, martensite morphology, and hysteresis $[8,10]$. High resolution TEM images in Figs.2a and $2 \mathrm{~b}$ show the average precipitate sizes after aging at $200^{\circ} \mathrm{C}$ for $1 \mathrm{~h}$ and $3 \mathrm{~h}$ to be $4-6 \mathrm{~nm}$ and $6-9 \mathrm{~nm}$, respectively.

Uniaxial tensile tests were performed at room temperature using an electro-mechanical MTS load-frame to characterize the superelastic response. Tensile strain was measured with an MTS LX1500 laser extensometer with laser tags directly attached to the wire. Gage length of the wires was $50 \mathrm{~mm}$. Specimens were deformed at a nominal strain rate of $5 \times 10^{-4} \mathrm{~s}^{-1}$, first to $0.5 \%$ strain, unloaded, then loaded again to $1 \%$ and unloaded. Following this procedure, the applied 
strain level was increased in $1 \%$ increments and the specimens were tested until failure. These incremental strain experiments were utilized to investigate the effect of aging condition on the stress induced martensitic transformation. From these incremental tests, superelastic properties of the wires, such as critical stress for SIM $\left(\sigma_{\mathrm{SIM}}\right)$, stress hysteresis, superelastic strain $\left(\sigma_{\mathrm{SE}}\right)$, elastic strain $\left(\sigma_{\mathrm{E}}\right)$, and irrecoverable strain $\left(\sigma_{\text {irrec }}\right)$ were determined.

Figs.3a-3c show the stress-strain response of $\mathrm{Fe}_{43.5} \mathrm{Mn}_{34} \mathrm{Al}_{15} \mathrm{Ni}_{7.5}$ wires at room temperature after aging at $200^{\circ} \mathrm{C}$ for (a) $1 \mathrm{~h}$, (b) $3 \mathrm{~h}$ and (c) $24 \mathrm{~h}$. $\sigma_{\text {SIM }}$, determined from the first loading cycles, are plotted as a function of increasing aging time at $200^{\circ} \mathrm{C}$, as shown in Fig. $3 \mathrm{~d}$. The $\sigma_{\mathrm{SIM}}$ level increases monotonically with increasing aging time for short duration aging, plateauing around $600 \mathrm{MPa}$ for aging treatments longer than $5 \mathrm{~h}$. The increase in transformation stress is attributed to a decrease in transformation temperatures, which are dependent on the size of the precipitates and the composition change in the matrix upon precipitation [8].

Previous studies on rolled polycrystalline sheets with similar aging treatments demonstrated maximum transformation stress levels around $200 \mathrm{MPa}$ [7], which is significantly lower than $600 \mathrm{MPa}$ observed in the present study. It has been reported that a random texture is developed after cold rolling in these alloys [7]. Wire drawing, on the other hand, results in a [110] texture after 75\% cold work as shown in the Fig.1c, and a similar [110] was also reported by Omori et al. in FeMnAlNi wires [19]. Since both sample forms have bamboo structured grains, overall deformation properties of both materials are expected to be highly dependent on individual grain orientations leading to different $\sigma_{\text {SIM }}$ values even though they are aged under the same conditions.

In superelasticity tests, the stress hysteresis is defined as the difference between the stress levels for stress-induced forward and reverse martensitic transformations during loading and unloading, respectively. This is a measure of energy dissipation during transformation. To investigate the effect of nano-precipitates on stress hysteresis, the stress hysteresis at $3 \%$ applied strain is plotted as a function of increasing aging time in Fig.4a. Clearly, the stress hysteresis decreases with aging time from $1 \mathrm{~h}$ to $3 \mathrm{~h}$, but after $3 \mathrm{~h}$ it increases monotonically. The decrease in stress hysteresis during aging from 1 to $3 \mathrm{~h}$ was also previously observed in FeMnAlNi single crystals oriented along the $<001>$ direction [8]. In this study, the $200^{\circ} \mathrm{C} 3 \mathrm{~h}$ heat treatment was reported to be the peak aging condition where the best superelastic response was observed [8]. In both the single crystalline and oligocrystalline materials, coherent precipitates lower the 
hysteresis and improves recoverability. Compared to aging for $3 \mathrm{~h}$, the observation of irrecoverable strain in the $200^{\circ} \mathrm{C} / 1 \mathrm{~h}$ aged sample after $5 \%$ strain (Fig.3a) indicates that matrix strength is not sufficient to prevent dislocation generation during transformation, which in turn increases energy dissipation.

After aging for times longer than $3 \mathrm{~h}$ we observe an increase in the stress hysteresis. This is due to higher frictional resistance to interfacial motion in the matrix due to the coarsening of precipitates [8,22], leading to higher energy dissipation. At a given aging condition, the hysteresis generally increases with applied strain level (Fig.4b), which is expected due to a larger transforming volume fraction of austenite and greater energy dissipation due to martensite variant-variant interactions [23]. The decrease in hysteresis between 2 and 3\% applied strains is likely caused by the training effect due to the initial superelastic increments. With a proper aging time and temperature $\left(200^{\circ} \mathrm{C} 24 \mathrm{~h}\right)$ it is shown here that FeMnAlNi wires can transform and recover up to $6.7 \%$ strain with a critical stress level of $600 \mathrm{MPa}$. This strength level with low hysteresis has not been previously reported in polycrystalline FeMnAlNi superelastic wires or sheets.

In all aging conditions studied here, the strain level at fracture does not change notably during the incremental strain experiments, and the average value is about $7 \%$. The maximum recoverable strain for each case is mostly dictated by the failure of the samples. Therefore, it is not possible to conclude how aging time affects the maximum recoverable strain levels. Figs.3b and $3 \mathrm{c}$ show that samples failed at 6 to $7 \%$ strain level while transformation is still in the first plateau region before the onset of hardening. This also suggests that the stress induced phase transformation may not be fully complete. Local stress concentrations near grain boundaries due to the martensite reorientation and detwinning, and in particular at the few triple junctions that exists in the samples, are responsible for the failure of the samples.

The superelastic stress-strain curves in Fig.3a, 3b and 3c show serrated response, which is more pronounced during the forward transformation. Similar serrated stress strain behaviors were observed previously in other FeMnAlNi alloys as well as in magnetic SMAs such as NiMnGa [24,25]. Omori et al. reported serrated stress-strain behavior in FeMnAlNi polycrystalline wires with a d/D ratio greater than one [19]. They also observed that serrations increased as the grain size to diameter ratio increased. These serrations were attributed to the 
nucleation barriers for martensitic transformation. Vollmer et al. [16] observed similar behavior in FeMnAlNi polycrystalline rolled tension samples. They were able to link each stress drop to the transformation of a single oligocrystalline grain into a single variant martensite [16]. However, in the present study, we only observe pronounced serrations in the samples that are aged at $200^{\circ} \mathrm{C}$ for $3 \mathrm{~h}$ and longer. Serrated flow, while present in samples aged at $200^{\circ} \mathrm{C}$ for $1 \mathrm{~h}$, was much finer in scale and less pronounced despite the large bamboo structured grains (the d/D ratio was higher than 8). Therefore, the size of the nano-precipitates seems to have an effect on the serrated flow behavior in these materials.

Serrated deformation behavior has also been observed in NiMnGa [24,25], however the serrations were linked to the surface roughness of the samples. The damaged surface layer resulting from spark plasma cutting or introduced via surface preparation can become stress concentrators, act as finely dispersed pinning sites for twin boundaries, and limits the ability of the martensite to coarsen. When the surface damage is removed, the twin boundaries rapidly propagate until they are stopped by the defects within the matrix and the twins become coarser [24]. Each pinning event results in a small stress increase and stress relaxation; however, this stress change is usually small as compared to what is observed for the FeMnNiAl samples aged $3 \mathrm{~h}$ and longer. Therefore, in the present case, the large stress drops are believed to be related to the transformation of an individual austenite grain to a single variant martensite. Small stress drops are likely to be influenced by the surface roughness of the wires. When the nanoprecipitates are small and the matrix is relatively soft, the martensite phase front propagates continuously leading to smoother stress-strain response.

The major findings of the current study can be summarized as follows:

(1) The superelastic properties of FeMnAlNi oligocrystalline wires, such as transformation stress and hysteresis, are highly dependent on the volume fraction and size of nanoprecipitates. As the aging time increases, the transformation stress increases, while the hysteresis can increase or decrease depending on the aging time.

(2) Aging at $200^{\circ} \mathrm{C}$ for 24 hours results in a $600 \mathrm{MPa}$ transformation stress with a fully recoverable superelastic strain up to $6.7 \%$. This recoverable strain with high strength levels has not been previously reported in FeMnAlNi polycrystalline samples and they are on par with those observed in commercial NiTi shape memory alloy wires. 


\section{Acknowledgements}

This work was supported by National Science Foundation - International Materials Institute

Program through the Grant No DMR 08-44082, Office of Specific Programs, Division of Materials Research, Arlington, Virginia. RDN gratefully acknowledges support from the NASA Transformative Aeronautics Concepts Program, Transformational Tools \& Technologies Project.

\section{References}

[1] K. Otsuka, C.M.C.M. Wayman, Shape Memory Materials, Cambridge University Press, 1999.

[2] K. Otsuka, X. Ren, Prog. Mater. Sci. 50 (2005) 511-678.

[3] T. Tadaki, C.M. Wayman, Scr. Metall. 14 (1980) 911-914.

[4] J. Frenzel, E.P. George, A. Dlouhy, C. Somsen, M.F.X. Wagner, G. Eggeler, Acta Mater. 58 (2010) 3444-3458.

[5] T. Maki, K. Kobayashi, M. Minato, I. Tamura, Scr. Metall. 18 (1984) 1105-1109.

[6] Y. Tanaka, Y. Himuro, R. Kainuma, Y. Sutou, T. Omori, K. Ishida, Science. 327 (2010) $1488-1490$.

[7] T. Omori, K. Ando, M. Okano, X. Xu, Y. Tanaka, I. Ohnuma, R. Kainuma, K. Ishida, Science. 333 (2011) 68-71.

[8] L.W. Tseng, J. Ma, B.C. Hornbuckle, I. Karaman, G.B. Thompson, Z.P. Luo, Y.I. Chumlyakov, Acta Mater. 97 (2015) 234-244.

[9] L.W. Tseng, J. Ma, S.J. Wang, I. Karaman, M. Kaya, Z.P. Luo, Y.I. Chumlyakov, Acta Mater. 89 (2015) 374-383.

[10] J. Ma, B.C. Hornbuckle, I. Karaman, G.B. Thompson, Z.P. Luo, Y.I. Chumlyakov, Acta Mater. 61 (2013) 3445-3455.

[11] S. Miyazaki, T. Kawai, K. Otsuka, J. Phys. Colloq. 43 (1982) 813-818.

[12] J.L. Liu, H.Y. Huang, J.X. Xie, Mater. Des. 64 (2014) 427-433.

[13] L.W. Tseng, J. Ma, S.J. Wang, I. Karaman, Y.I. Chumlyakov, Scr. Mater. 116 (2016) $147-151$.

[14] S. Miyazaki, T. Kawai, K. Otsuka, Scr. Metall. 16 (1982) 431-436. 
[15] J. Ma, B. Kockar, A. Evirgen, I. Karaman, Z.P. Luo, Y.I. Chumlyakov, Acta Mater. 60 (2012) 2186-2195.

[16] M. Vollmer, C. Segel, P. Krooß, J. Günther, L.W. Tseng, I. Karaman, A. Weidner, H. Biermann, T. Niendorf, Scr. Mater. 108 (2015) 23-26.

[17] S.M. Ueland, C.A. Schuh, J. Appl. Phys. 114 (2013) 53503.

[18] S.M. Ueland, Y. Chen, C.A. Schuh, Adv. Funct. Mater. 22 (2012) 2094-2099.

[19] T. Omori, M. Okano, R. Kainuma, APL Mater. 1 (2013) 32103.

[20] S.M. Ueland, C.A. Schuh, Acta Mater. 60 (2012) 282-292.

[21] Y. Chen, X. Zhang, D.C. Dunand, C.A. Schuh, Appl. Phys. Lett. 95 (2009) 171906.

[22] R.F. Hamilton, H. Sehitoglu, Y. Chumlyakov, H.J. Maier, Acta Mater. 52 (2004) 33833402 .

[23] M. Vollmer, P. Krooß, M.J. Kriegel, V. Klemm, C. Somsen, H. Ozcan, I. Karaman, A. Weidner, D. Rafaja, H. Biermann, T. Niendorf, Scr. Mater. 114 (2016) 156-160.

[24] M. Chmielus, K. Rolfs, R. Wimpory, W. Reimers, P. Müllner, R. Schneider, Acta Mater. 58 (2010) 3952-3962.

[25] M. Chmielus, P. Müllner, Mater. Sci. Forum 684 (2011) 175-199. 

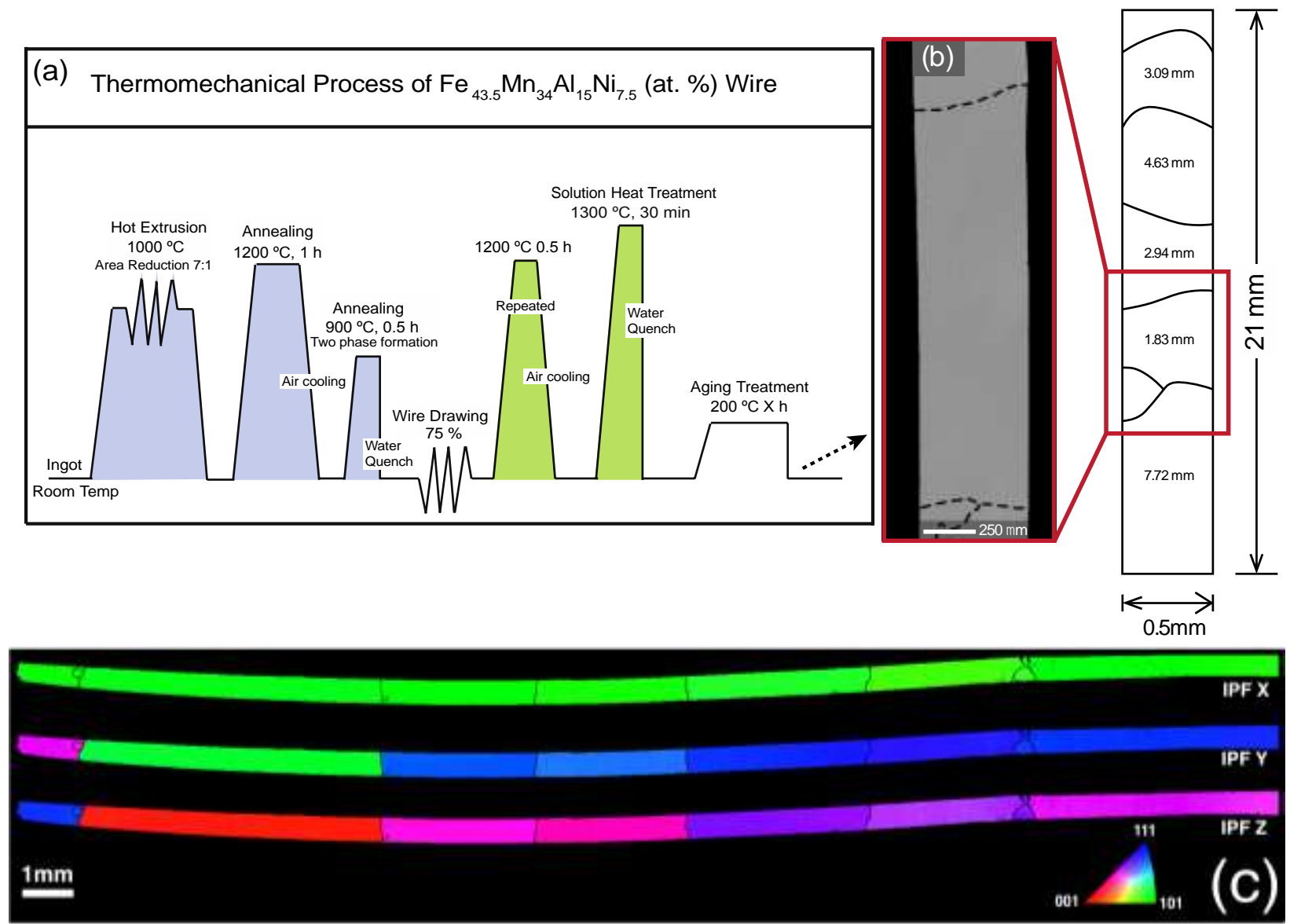

Figure 1: (a) Thermomechanical processing history of Fe-34\% Mn-15\%Al-7.5\%Ni (at. \%) superelastic wire. (b) Final grain sizes and distribution in a representative Fe-34\% Mn-25\% Al$7.5 \% \mathrm{Ni}($ at. \%) superelastic wire after cyclic grain growth treatment and final solution heat treatment at $1300{ }^{\circ} \mathrm{C}$ for $30 \mathrm{~min}$ (as defined in (a)). (c) EBSD orientation mapping of a $\mathrm{Fe}_{43.5} \mathrm{Mn}_{34} \mathrm{Al}_{15} \mathrm{Ni}_{7.5}$ (at.\%) wire aged at $200{ }^{\circ} \mathrm{C}$ for $24 \mathrm{~h}$ after tensile superelastic test (the superelastic response is shown in Fig. 3c). The colors represent the crystal directions parallel to the drawing direction (IPFX), the transverse direction (IPFY) and the normal direction (IPFZ), given in the stereographic triangle. 

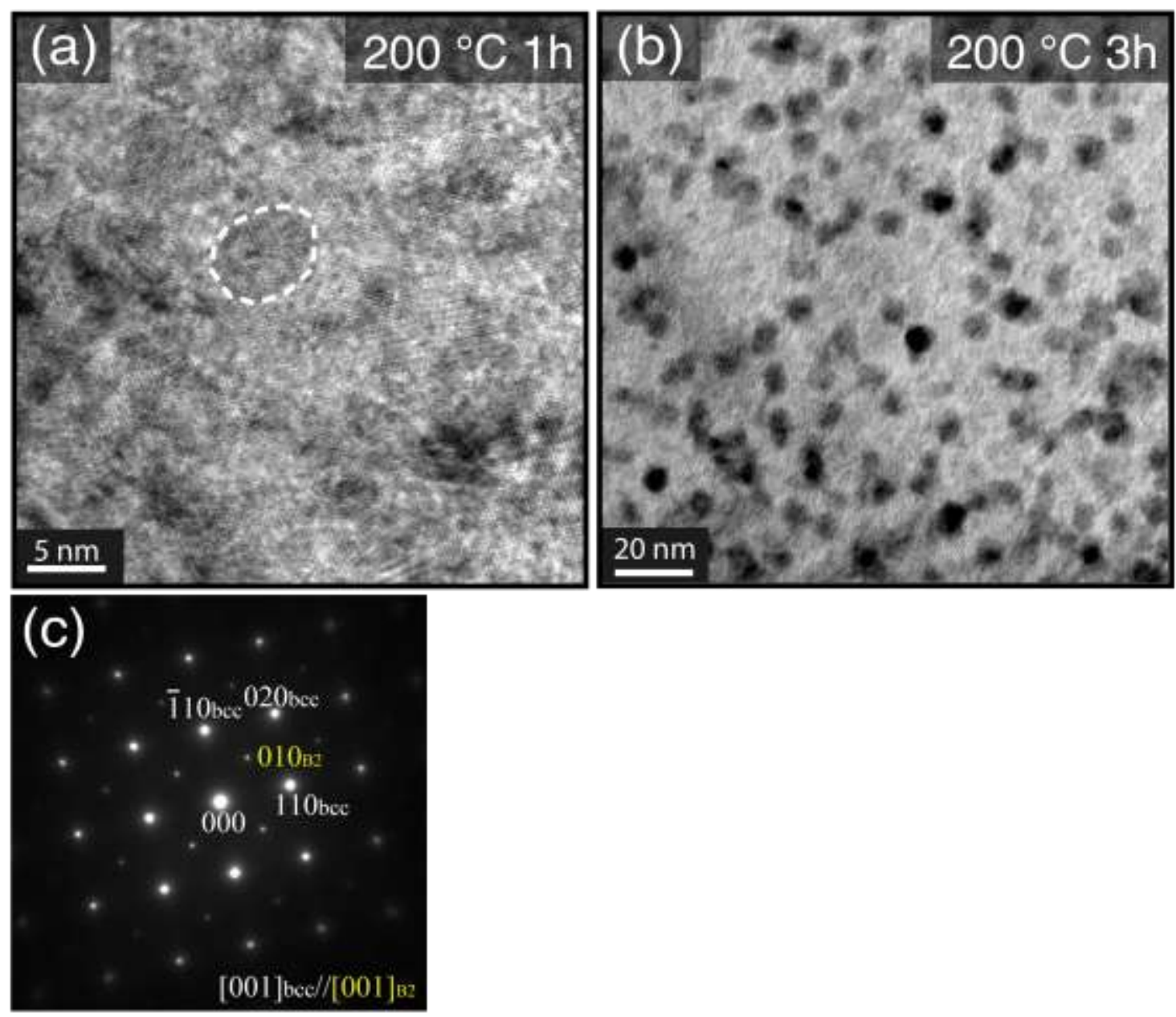

Figure 2: Microstructure of the Fe-34\%Mn-15\% Al-7.5\% Ni (at. \%) alloy; (a) High resolution TEM image showing B2 precipitates after aging at $200{ }^{\circ} \mathrm{C}$ for $1 \mathrm{~h}$. (b) Conventional TEM image of the B2 precipitates after aging at $200{ }^{\circ} \mathrm{C}$ for $3 \mathrm{~h}$. (c) Selected area diffraction pattern of a single BCC matrix grain oriented along the [001] direction after solution heat treatment [8]. 

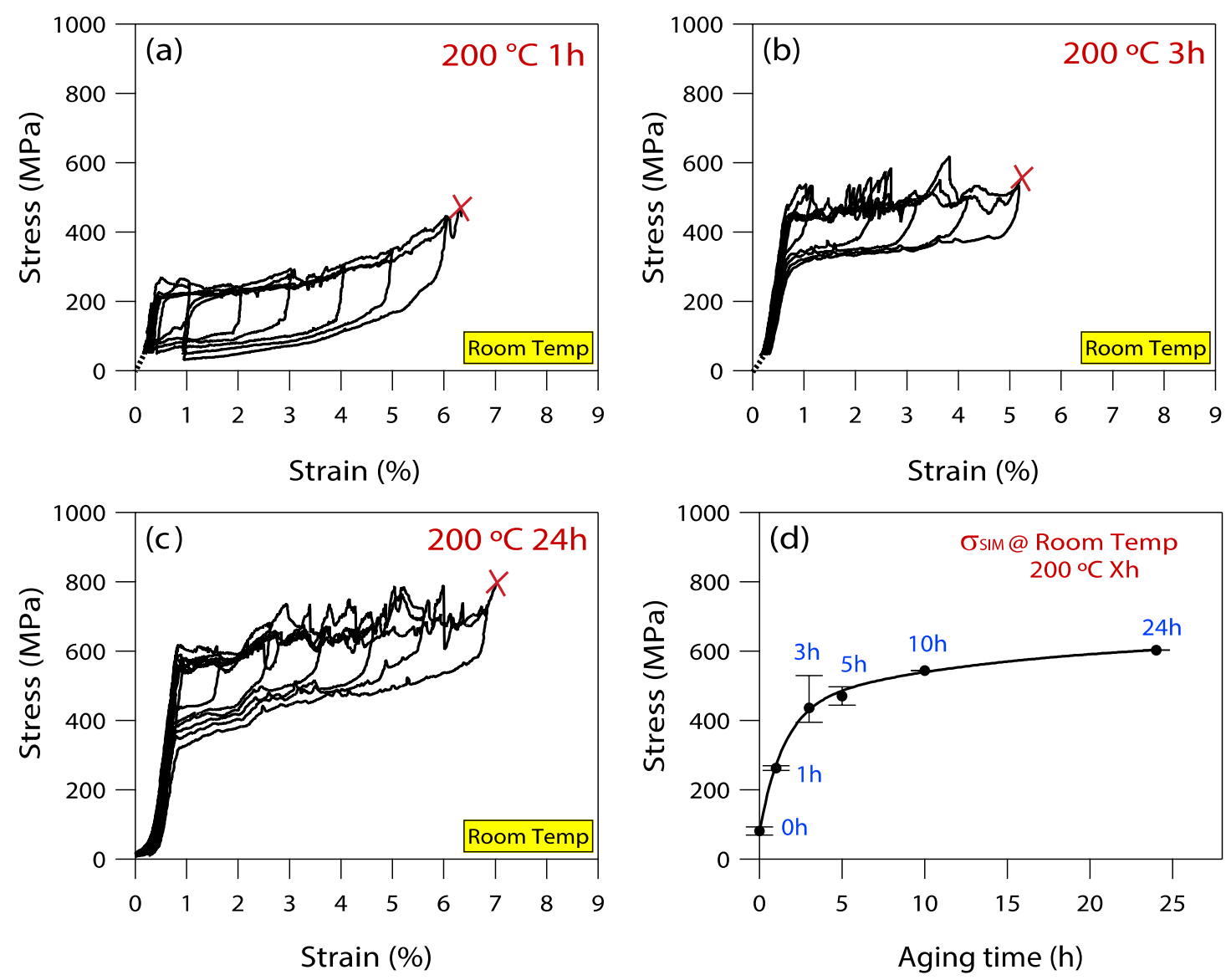

Figure 3: Room temperature tensile superelastic responses of $\mathrm{Fe}-34 \% \mathrm{Mn}-15 \% \mathrm{Al}-7.5 \% \mathrm{Ni}$ (at. $\%$ ) wire subjected to the cyclic abnormal grain growth method, followed by solution heat treatment at $1300^{\circ} \mathrm{C}$, and aging at $200^{\circ} \mathrm{C}$ for (a) $1 \mathrm{~h} \mathrm{(b)} 3 \mathrm{~h}$ and (c) $24 \mathrm{~h}$. (d) Summary of the critical stress for stress induced martensitic transformation $\left(\sigma_{\mathrm{SIM}}\right)$ versus aging time of the $\mathrm{Fe}$ $34 \% \mathrm{Mn}-15 \% \mathrm{Al}-7.5 \% \mathrm{Ni}$ (at. \%) wires after cyclic abnormal grain growth and aging at $200^{\circ} \mathrm{C}$. 

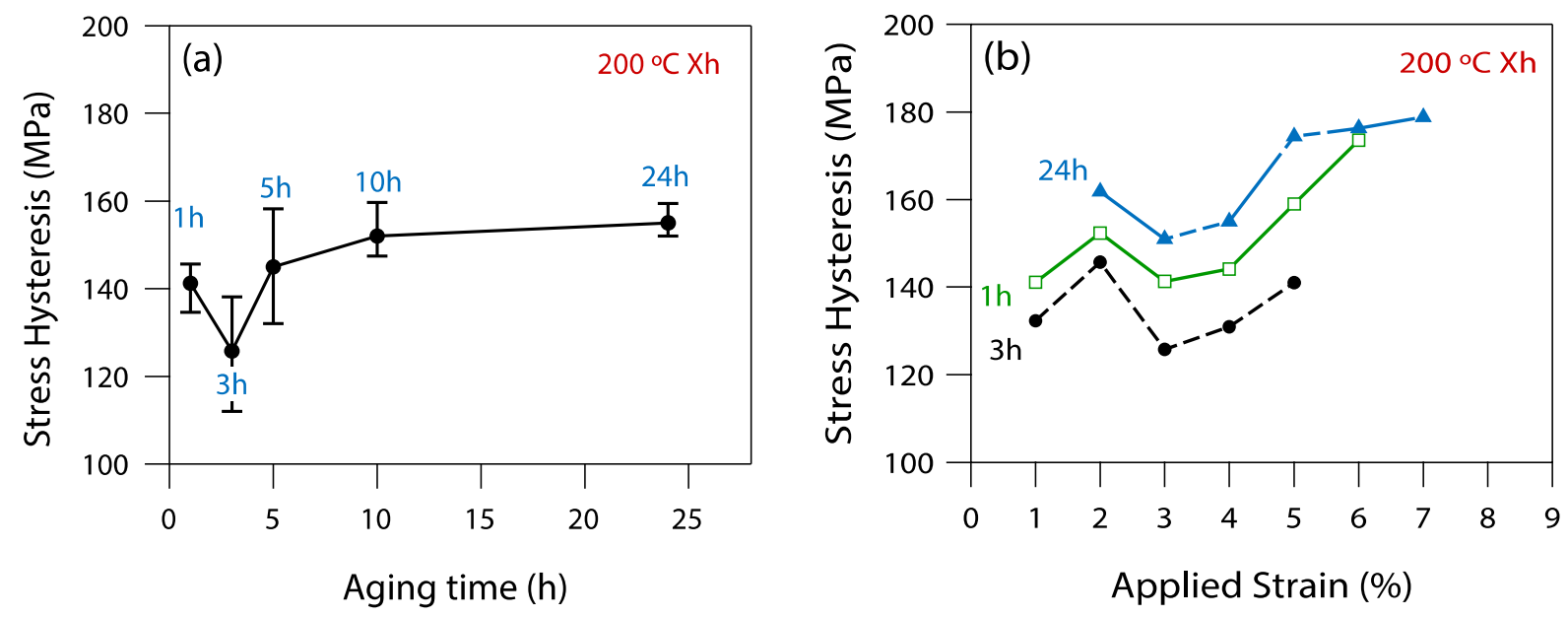

Figure 4: Stress hysteresis of $\mathrm{Fe}-34 \% \mathrm{Mn}-15 \% \mathrm{Al}-7.5 \% \mathrm{Ni}$ (at. \%) wires during superelastic experiments. (a) Change of stress hysteresis with aging time at $200{ }^{\circ} \mathrm{C}$. Stress hysteresis is calculated at 3\% applied strain in each aging condition. (b) The relationship between the stress hysteresis and the applied strain level for three different aging conditions. 


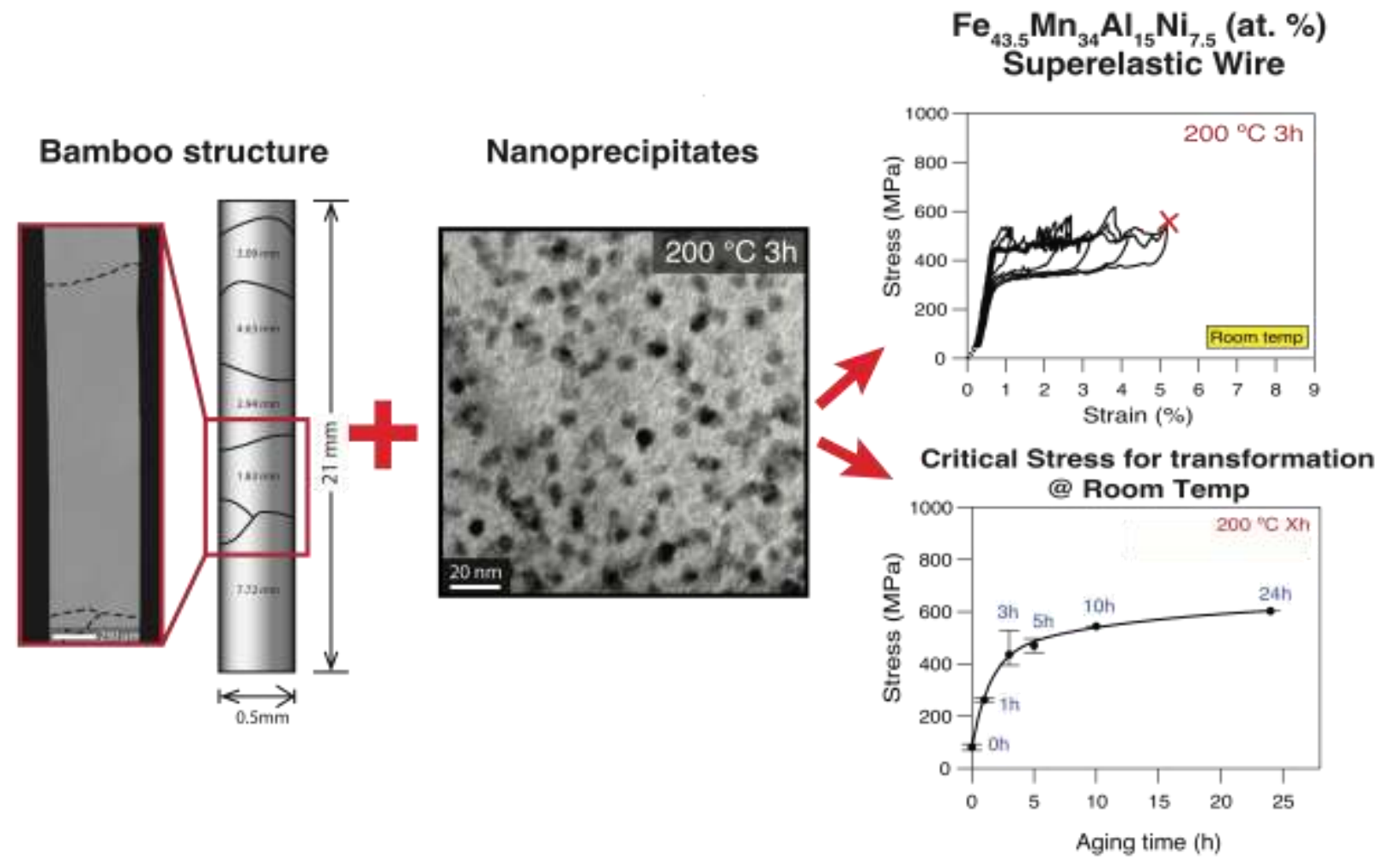

